Kansas State University Libraries

New Prairie Press

\title{
MODEL BUILDING IN MULTI-FACTOR PLANT NUTRITION EXPERIMENTS
}

L. M. Olson

W. W. Stroup

E. T. Paparozzi

M. E. Conley

See next page for additional authors

Follow this and additional works at: https://newprairiepress.org/agstatconference

Part of the Agriculture Commons, and the Applied Statistics Commons

\section{(c) (1) $\Theta(9$}

This work is licensed under a Creative Commons Attribution-Noncommercial-No Derivative Works 4.0 License.

\section{Recommended Citation}

Olson, L. M.; Stroup, W. W.; Paparozzi, E. T.; and Conley, M. E. (2001). "MODEL BUILDING IN MULTI-FACTOR PLANT NUTRITION EXPERIMENTS," Conference on Applied Statistics in Agriculture. https://doi.org/ $10.4148 / 2475-7772.1224$

This is brought to you for free and open access by the Conferences at New Prairie Press. It has been accepted for inclusion in Conference on Applied Statistics in Agriculture by an authorized administrator of New Prairie Press. For more information, please contact cads@k-state.edu. 


\section{Author Information}

L. M. Olson, W. W. Stroup, E. T. Paparozzi, and M. E. Conley 


\title{
Applied Statistics in Agriculture
}

\section{MODEL BUILDING IN MULTI-FACTOR PLANT NUTRITION EXPERIMENTS}

\author{
L. M. Olson ${ }^{1}$, W. W. Stroup ${ }^{1}$, E. T. Paparozzi ${ }^{2}$, and M. E. Conley ${ }^{2}$ \\ ${ }^{1}$ Department of Biometry, University of Nebraska-Lincoln \\ ${ }^{2}$ Department of Agronomy and Horticulture, University of Nebraska-Lincoln
}

\begin{abstract}
Often, the goal of plant science experiments is to model plant response as a function of quantitative treatment factors, such as the amount of nutrient applied. As the number of factors increases, modeling the response becomes increasingly challenging, especially since the resources available for such experiments are usually severely limited. Typical methods of analysis, notably second-order response surface regression, often fail to accurately explain the data. Alternatives such as non-linear models and segmented regression have been used successfully with two-factor experiments (Landes, et. al, 1999). This paper extends previous work to three-and-more factor experiments. Models are assessed to explain the relationship between the levels of nutrients applied and leaf, root, and shoot responses of Poinsettias from an experiment conducted by horticultural researchers at the University of Nebraska-Lincoln. These data illustrate problems that are representative of those that plant researchers typically face. Multiple regression using the Hoerl function proved to be especially useful. These analyses suggest a feasible approach to design of experiments suitable for a wide variety of plant science applications with multiple factors and limited resources.
\end{abstract}

Key Words: Factorial experiment, response surface methods, nonlinear regression, incomplete factorial design

\section{Introduction}

Imagine that you are a commercial grower of ornamental plants. You grow the Poinsettia that people buy for Christmas, the plants they buy for their garden, the flowers they buy for Valentine's Day, Mother's Day or to patch up misunderstandings with a significant other. These plants need nutrients and water. Possibly, they also need applications of pest control or growth regulators. If a plant receives too little of a critical nutrient, it will show signs of deficiency and be unacceptable to the consumer even if it doesn't die. If too much is applied, it is wasteful. The extra expense cuts into your profit margin and may work its way into the environment as a source of pollution.

Commercial growers and plant science researchers have a common goal: to study the effect of several factors such as nutrients on plant response. The commercial grower wants to find the optimum combination to get the best plant for the lowest cost. The scientist wants to understand how several nutrients, or nutrient-water-pest control-growth regulator systems affect various plant responses of interest, such as elemental concentrations, deficiency symptoms, appearance, etc. The key word is systems: these objectives require working with several factors at a time. Because these factors are typically mutually interdependent, quantifying plant response as a function of several treatment factors often requires estimating three-way and possibly higher-order interactions. Usually, these studies must be done with severely limited resources. 
For statisticians, this appears to be a standard response surface problem, for which there is a plethora of well-accepted approaches, and ample literature documenting these methods over the past half century. See, for example, Khuri and Cornell (1996). Standard response surface methods assume that the response-treatment factor relationship can be adequately characterized by a second-order polynomial regression, that is

$$
y=\beta_{0}+\sum_{i=1}^{N} \beta_{i} X_{i}+\sum_{i=1}^{N} \beta_{i i} X_{i}{ }^{2}+\sum_{i<j=1}^{N} \beta_{i j} X_{i} X_{j}
$$

where $y$ is the response variable; $\mathrm{X}_{\mathrm{i}}$ denotes the level of the $\mathrm{i}^{\text {th }}$ treatment factor, $i=1,2, \ldots, N ; N$ is the number of treatment factors; and the $\beta$ s are the regression coefficients. The standard response surface model (1) thus assumes that for any treatment factor, the response over its levels can be adequately modeled by a quadratic regression and all effects more complex than 2way linear $\times$ linear interactions are negligible. If model (1) is adequate, then response surface designs such as fractions of $3^{\mathrm{N}}$ factorials, central-composite designs, face-balanced cube designs, or Box-Behnken designs can be used to address the problem of limited resources.

Appearances can be deceiving. Response surface methods following from model (1) are often unsuitable for plant nutrition experiments. Mead and Pike (1975) noted that response surface methods were used only in a small fraction of agricultural research applications where they would seem to be appropriate, a situation which is still largely true. Among several possible reasons, Mead and Pike suggested that one possibility was that response surface methods do not adequately address researchers' objectives. Landes, et. al. (1999) considered this point specifically for plant nutrition research. Looking at experiments with two nutrition treatment factors, nitrogen $(\mathrm{N})$ and sulfur $(\mathrm{S})$, model (1) was found to be severely inadequate to characterize treatment effects for several crucial response variables in these experiments. Nonlinear models, described in section 2, were found to give adequate fits. Landes, et. al. speculated on designs that might be appropriate. Stroup and Paparozzi (2000) pursued the design issue by constructing three-factor data sets similar in response structure to the N-S experiments. They identified three-factor non-linear models that fit adequately and developed procedures to construct incomplete factorial designs that 1) provided sufficient data to accurately estimate the same non-linear models used for the full factorial data, while at the same time 2) addressing the problem of limited resources.

While the methods of Stroup and Paparozzi are promising, they are based on hypothetical multi-factor data extrapolated from two-factor experiments. The purpose of this paper is to use "live data" from a four-factor plant nutrition experiment conducted at the University of Nebraska Department of Horticulture in 1998 and 1999 to assess the performance of Stroup and Paparozzi's proposed methods. Section 2 of this paper reviews the main ideas from Landes, et. al. and Stroup and Paparozzi. Section 3 describes the four-factor experiment and the approaches used to model the data. Section 4 considers subsets of the data suggested by the incomplete factorial designs from Stroup and Paparozzi and compares results obtained from the full data versus the incomplete factorial data. Section 5 presents summary and conclusions regarding response surface methods based on suitable models, as opposed to model (1), for plant nutrition experiments.

\section{Background}


Landes, et. al. (1999) considered data from a two-factor plant nutrition experiment conducted at the University of Nebraska-Lincoln Department of Horticulture by Macz (1997). The experiment was a 4 x 5 factorial with 4 levels of $N(50,100,150$, and 200 ppm) and 5 levels of $S(0,5,10,20$, and 80$)$. The treatment design and pattern of responses are typical of research conducted by several graduate students under Dr. Paparozzi's supervision.

Figure 1 shows a plot of the mean leaf area at 8 weeks for the various treatment combinations. While the response to increasing levels of $\mathrm{N}$ is approximately linear, the response to $S$ is strongly non-linear, with a steep increase at the lowest levels of $S$ and a plateau at higher

levels of S. Two models were fit to the data: the first was the standard response surface model, a second-order polynomial regression described by equation (1) above; the second model combined a linear regression for the response to $\mathrm{N}$ with a Gompertz equation for the response to $\mathrm{S}$, resulting in the following:

$$
y=\left(\theta_{\min }+\theta_{\mathrm{N}} \mathrm{N}\right) \exp \left\{-\theta_{\text {rng }} \exp \left(\theta_{\mathrm{S}} \mathrm{S}\right)\right\}
$$

Figure 2 shows the predicted values obtained from fitting to the data using models (1) and (2). The standard response surface model (1) clearly misrepresents the data, whereas model (2) adequately portrays the main features of the data.

Stroup and Paparozzi (2000) extended this approach to three factors. Figure 3 shows a hypothetical set of data based on the response pattern in the Macz leaf area data and repeated in many other experiments in Paparozzi's research. The data in Figure 3 have two important characteristics typical of plant nutrition data:

1. the responses are strongly non-linear over the various factors, and

2. there is a pronounced three-way interaction, which occurs because all three factors are limiting: the lowest level of each factor produces minimal response for all levels of the other two factors, but as the level of any one factor increases, the response surface over the other two factors changes.

Any model that fails to incorporate both characteristics is unsuitable. Stroup and Paparozzi presented three models. The first was a three-factor extension of the Mitscherlich model:

$$
y=\alpha-\beta^{\left(\gamma_{1}^{X_{1}}+\gamma_{2}{ }^{X_{2}}+\gamma_{3}{ }^{X_{3}}+\gamma_{4}{ }^{X_{1} X_{2}}+\gamma_{5}{ }^{X_{1} X_{3}}+\gamma_{6}{ }^{X_{2} X_{3}}+\gamma_{7}{ }^{X_{1} X_{2} X_{3}}\right)}
$$

The second was a three-factor Gompertz model:

$$
y=\alpha e^{-\beta e^{-\left(\gamma_{1} X_{1}+\gamma_{2} X_{2}+\gamma_{3} X_{3}+\gamma_{4} X_{1} X_{2}+\gamma_{5} X_{1} X_{3}+\gamma_{6} X_{2} X_{3}+\gamma_{7} X_{1} X_{2} X_{3}\right)}}
$$

Both the Mitscherlich and Gompertz models produced nearly identical fit of the data. Figure 4 shows the predicted values obtained from these models. The third model is a three-factor extension of the Hoerl equation (Daniel and Wood, 1980), whose linearized form is given by

$$
\begin{aligned}
\log (y)=\beta_{0} & +\sum_{i=1}^{3}\left(\alpha_{i} X_{i}+\beta_{i} L_{i}\right)+\sum_{i<j=1}^{3}\left(\alpha_{i j} X_{i} X_{j}+\beta_{i j} L_{i} L_{j}\right) \\
& +\alpha_{123} X_{1} X_{2} X_{3}+\beta_{123} L_{1} L_{2} L_{3}
\end{aligned}
$$

where $\mathrm{L}_{\mathrm{i}}=\log \left(\mathrm{X}_{\mathrm{i}}\right), i=1,2,3$. Figure 5 shows the predicted values obtained by fitting the Hoerl model to the data in Figure 3. Although the Hoerl model's fit is not a good as the Mitscherlich or Gompertz, it does represent the essential features of the data well enough to permit accurate 
conclusions and reasonable decisions. Also, the Hoerl function is extremely flexible and can be used when other non-linear models fail, as the example in the next sections illustrate.

Stroup and Paparozzi also discussed strategies for designing incomplete factorial experiments to conduct plant nutrition research efficiently. They found that standard response surface designs were not suitable for estimating models (3), (4), or (5). However, by augmenting designs such as the central-composite, the face-balanced cube, and the Box-Behnken design with additional points to permit characterizing highly non-linear response profiles and multi-factor interactions, they were able to construct useful designs. Section 4 shows an example for a fourfactor experiment.

The focus of this paper is to subject the conceptual ideas of Stroup and Paparozzi to a "reality check" using data from a four-factor plant nutrition experiment.

\section{Model Fitting with a Four-Factor Experiment}

To test the modeling approaches developed by Landes, et.al. (1999) and Stroup and Paparozzi (2000) in a more demanding multi-factor setting, a $3^{4}$ factorial experiment on the Freedom Red cultivar of Poinsettia was conducted at the University of Nebraska-Lincoln Department of Horticulture. The four factors were $\mathrm{N}$ with levels 50, 125, and 200; S with levels 0, 12.5, and 25; Fe with levels 0, 1.375, and 3.0; and Mn with levels 0, 0.77, and 1.5. The levels for each nutrient were chosen based on past research done by Dr. Paparozzi and various graduate students under her supervision. This past research, e.g. Macz (1997), has documented the effect of macro nutrients $\mathrm{N}$ and $\mathrm{S}$. The objective of this experiment was to additionally characterize the effects of micro nutrients $\mathrm{Fe}$ and $\mathrm{Mn}$ and their possible interaction with $\mathrm{N}$ and $\mathrm{S}$.

The experimental facility had a capacity to handle 100 plants. The experiment was conducted so that each plant was an experimental unit. Therefore, all $3^{4}=81$ treatment combinations were applied to at least one plant. In addition, 19 treatment combinations were assigned to replicate plants. Treatment combinations were selected for replication based on either plant physiological or statistical considerations. For example, treatment combinations where all the nutrients are at the lowest levels were considered likely to produce deficiency symptoms, which could make it difficult for the plant to survive for the duration of the experiment. Without these specific points potential information would have been lost on a treatment combination. Replication improved the chance of having a valid observation for such treatment combinations.

The response variables were elemental concentrations in roots and shoots of the Poinsettia plants. For the purposes of this paper, all response variables were analyzed using the following steps:

1. A second-order response surface model (1) was fit

2. Lack-of-fit was evaluated

3. Higher-order terms not contained in model (1), e.g. 2-way interactions with quadratic terms or 3-way or higher interactions that were statistically significant were noted.

The results of this analysis are summarized in Table 1 for the shoot data and Table 2 for the root data. Note that it is more the rule then the exception to have significant higher-order terms beyond the second order response model (1). For several elements there were three-way interactions along with non-linear two-way interactions.

For response variables for which the second order response surface model (1) is adequate, it would be appropriate to use standard response surface methodology for analysis and 


\section{Applied Statistics in Agriculture}

to reduce the number of experimental units in subsequent experiments. On the other hand, for those response variables for which model (1) is inadequate, a different approach is required. First, one must find a model that is adequate to characterize the data. Second, one must construct a design that permits estimating the model's parameters. The rest of this section illustrates the model selection process for one response variable. The next section shows the design considerations that follow. Boron concentration in the shoot was selected for this example, because the response was fairly complex and difficult to model. Hence, this example shows the full range of tools required. Other variables follow a similar approach.

Figure 6 shows a scatter plot of the boron data. On each graph the horizontal axis is the $\mathrm{S}$ axis and the vertical axis is the $\mathrm{N}$ axis. Moving across the page levels of $\mathrm{Mn}$ increase and moving down the page levels of Fe increase. Figure 7 is another view of the original data. The in-depth analysis consisted of the following steps:

1. Model diagnostics were used to determine if any outliers or influential points were present in the data. The purpose was to make sure that lack of fit was not an artifact of any influential or outlying points. In this step, two points were removed from the analysis. These were replicated points so no information was lost on any treatment combinations.

2. Evaluate the fit of the second order response model. The R-square is 0.71 and the mean square error is 33.60. Figure 8 shows the predicted values obtained from the model. Note that this model misrepresents the data in ways horticulturalists judge to be important. For example, at the lowest level on $\mathrm{Mn}$, there is a reduced response for 50 units of $\mathrm{N}$ relative to other $\mathrm{N}$ levels at the 0 level of $\mathrm{S}$. The second order model missed this feature.

3. Evaluate the fit of a polynomial model augmented with additional terms found to be statistically significant. These terms were $\mathrm{S} * \mathrm{Fe} * \mathrm{Fe}, \mathrm{S} * \mathrm{Mn} * \mathrm{Mn}, \mathrm{Fe}^{*} \mathrm{Mn} * \mathrm{Mn}$, $\mathrm{Fe}^{*} \mathrm{Fe} * \mathrm{Mn}, \mathrm{N} * \mathrm{~S} * \mathrm{Fe}, \mathrm{N} * \mathrm{~S} * \mathrm{Mn}, \mathrm{S} * \mathrm{Fe} * \mathrm{Mn}, \mathrm{S} * \mathrm{Fe} * \mathrm{Mn} * \mathrm{Mn}$ and $\mathrm{S} * \mathrm{Mn} * \mathrm{Fe}{ }^{*} \mathrm{Fe}$. The RSquare is 0.79 and the mean square error drops to 28.04. Figure 9 shows predicted values. Note that the augmented polynomial does a better job representing features of the data considered horticulturally important.

While the augmented polynomial improved the fit, utilizing such a model would require excessively large experiments (i.e. a full factorial with 3-5 levels per factor) and or prior knowledge of potential significance. This is not realistic once the number of factors and levels start to increase. Because the second order response surface model is inadequate and the augmented polynomial with additional points is impractical, another alternative is needed. Landes et al (1999) and Stroup and Paparozzi (2000) used Gompertz (3) and Mitscherlich (4) models. However, the boron data suggest that these models are inappropriate because of the absence of a rapid increase to plateau response. Following Stroup and Paparozzi, an alternative is the Hoerl model (5).

The Hoerl model yields an R-Square of 0.80 and a mean square error of 28.15. Figure 10 shows the predicted values. Table 3 gives the ANOVA and estimated model parameters. The Hoerl model represents the data well. There is also evidence of three-way and four-way interaction that would have been missed with the polynomial models. Also note that the 3-and 4-way terms in the Hoerl model do not require prior knowledge or the use of a full-factorial design. Thus, the Hoerl equation provides a promising model. We now turn to the problem of selecting a manageable design. This is the topic of the next section. 


\section{Design}

As stated earlier, if the second order response surface model was adequate one could use well-known response surface designs, such as face balance cube, central composite design and fractional factorials. However, as shown in the previous section this is clearly not the case. Recall from Section 2 that Stroup and Paparozzi (2000) suggested augmenting a face balance cube with additional design points to permit estimation of multi-factor models such as the Hoerl model (5) fit in the previous section. Figure 11 shows such a design. The outer cube is the foundation of the face balanced cube. The number 1, 3, and 5 represent low, medium and high doses of a factor. For example, for $\mathrm{N}$ these levels would be 50, 125, 200. Stroup and Paparozzi (2000) found out that three points are insufficient to estimate the multi-factor models useful in plant-nutrition, including the Hoerl. They recommended a minimum of four or five levels per factor as necessary to capture the shape of typical plant nutrient response curves. One such design placed an inner cube within the face-balance cube. In this case, the inner cube is a $2^{4}$ factorial design whose levels are 2 and 4, i.e. one level (2) midway between the low and medium levels ( 1 and 3 ) and the other level (4) midway between the medium and high levels. We called this design CELEPSO, named for the five people involved in this research. Elizabeth Conley and Dr. Ellen Paparozzi, who conducted the experiment, and Reid Landes, Dr. Walt Stroup, and Lana Olson who did the statistical analysis and conceptual development.

With the CELEPSO the number of experimental units is reduced from 81 to 41 treatment combinations. The real test of the design is to see how well it reproduces the second order response surface model (1) and the Hoerl Model (5) fit to that we fit to the original data. Figure 12 shows the predicted values from the second order model using the CELEPSO design. Figure 13 shows the predicted values from the Hoerl model with the CELEPSO design. Visually, both graphs are similar to the graphs that were obtained using the full data (Figure 8 for the secondorder polynomial; Figure 10 for the Hoerl equation). For the second order model, this is expected, since the face-balanced cube design even without being augmented is specifically intended to be used to estimate such models. The most important result here is that the CELEPSO design works equally well for data that require the more complex Hoerl model. Thus, the augmented face-balanced cube approach, of which the CELEPSO is an example, is not merely a design with intuitive appeal, but it seems to perform well in practice when used with "live" plant nutrition data. This is an extremely promising result for future, manageable, multifactor-nutrition research.

\section{Summary and Conclusions}

This example shows that it is possible to conduct efficient multi-factor plant nutrition experiments. While standard response surface methods based on second-order polynomial regression are clearly inappropriate, non-linear models using the basic principles of response surface methodology and response surface designs augmented to permit estimation of the parameters of these models can and do yield useful results. The modeling, analysis, and design issues for the Boron concentration variable used in this example are typical of other elemental concentrations measured in this experiment and of response variables observed in plant nutrition experiments in general. While non-linear models such as the Mitscherlich and Gompertz have intuitive appeal in nutrient-response settings and have been used successfully in past work, such as Landes, et. al. (1999), the response profiles observed for the four-factor data in this paper 
generally were not suitable candidates for these models. However, the Hoerl equation, because of its flexibility, worked quite well. The Boron example reported here is typical.

The approach of augmenting standard response surface designs to accommodate models with multi-way interactions, such as the four-factor Hoerl model used in this example, worked well. The specific design, a four-factor face-balanced cube augmented with a $2^{4}$ design at intermediate points, called the CELEPSO design in this paper, yielded an estimated model very close to that estimated from the full set of data. Assuming Stroup and Paparozzi's recommendation of four to five design points minimum per factor, the CELEPSO-type design would require 23 treatment combinations for a three-factor design versus at least $4^{3}=64$ treatment combinations for a full-factorial design, 41 treatment combinations versus $4^{4}=256$ for a fourfactor design, 75 treatment combinations versus $4^{5}=1024$ for a five-factor design, etc. Given plant-to-plant variability, we would recommend that treatment combinations be chosen using the augmented face-balance cube approach, or something similar, and that these points be replicated, rather than using higher-order interactions to estimate experimental error. The Boron data clearly show that non-negligible higher-order interactions do occur in plant nutrition data.

Further work is needed in the following areas. First, while the multi-factor Hoerl equation provides a very flexible addition to non-linear nutrient response models such as the Mitscherlich and Gompertz, other alternatives may emerge as experience is accumulated with these methods. The CELEPSO design, while effective, is an ad hoc design. Stroup and Paparozzi (2000) showed that the augmented face-balanced cube is not a D-optimal design for the Hoerl model. They constructed alternative designs with computer assisted procedures using SAS PROC OPTEX. One might envision a strategy to construct robust designs for the various models considered plausible in a given plant nutrition experiment. Whether the resulting designs are sufficiently more efficient than ad hoc designs like the CELEPSO to justify the extra effort is certainly of interest.

Finally, the analysis of all the elemental concentration data from this experiment needs to be completed and reported to the plant nutrition research community. Tables 1 and 2 make it clear that the methods illustrated for the Boron data are required for most of the other elemental concentration variables. Given that this methodology breaks new ground in the plant nutrition area, some effort will be required to familiarize plant nutritionists with this approach.

To summarize, the models illustrated in Section 3 of this paper along with the design approaches shown in Section 4 provide important tools for plant nutrition research. They make it possible to accurately characterize complex multi-factor data and to conduct experiments within the typical budget, size, and workload constraints that plant nutrition researchers typically face without the need to make unrealistic assumptions about higher-order interactions, or to spread the research over an excessively long time frame.

\section{References}

Daniel, C. and F.S. Wood, 1980. Fitting Equations to Data, $2^{\text {nd }}$ ed. New York: Wiley.

Khuri, A.I. and J.A. Cornell. 1996. Response Surfaces: Designs and Analyses. New York: Marcel Dekker, Inc. 
Landes, R.D., W.W. Stroup, E.T. Paparozzi, and M.E. Conley. 1999. "Nonlinear models for multi-factor plant-nutrition experiments." Proceedings, $11^{\text {th }}$ Annual Conference on Applied Statistics in Agriculture. Kansas State University, Manhattan, KS.

Macz, O. 1997. The Effect of Nitrogen and Sulfur Applications on Pot Chrysanthemum Production and Post-Harvest Performance. MS Thesis in Horticulture, University of Nebraska-Lincoln.

Mead, R. and D.J. Pike. 1975. "A review of response surface methodology from a biometric viewpoint." Biometrics 31: 803-851.

Stroup, W.W. and E.T. Paparozzi. 2000. "Multi-factor models for plant nutrition experiments." Presentation at 2000 Biometric Society East North American Regional Meetings, Chicago, IL. 
Table 1: Shoots

\begin{tabular}{|c|c|c|}
\hline $\begin{array}{l}\text { Response } \\
\text { Variable }\end{array}$ & & \\
\hline $\begin{array}{c}\text { Elemental } \\
\text { Concentration } \\
\text { in leaves }\end{array}$ & Significant non-linear 2-way or & $\begin{array}{c}\geq 3 \text {-way } \\
\text { interactions }\end{array}$ \\
\hline $\mathrm{N}$ & $\mathrm{N} * \mathrm{~S} * \mathrm{~S}, \mathrm{Fe}^{*} \mathrm{Fe}^{*} \mathrm{Mn}$ & $\mathrm{N} * \mathrm{Fe}^{*} \mathrm{Mn}$ \\
\hline $\mathrm{P}$ & n.s. & n.s. \\
\hline $\mathrm{Al}$ & n.s. & $\mathrm{N} * \mathrm{~S} * \mathrm{Fe}$ \\
\hline $\mathrm{K}$ & $\mathrm{N} * \mathrm{~N} * \mathrm{~S}$ & n.s. \\
\hline $\mathrm{Mg}$ & $\mathrm{N}^{*} \mathrm{~N} * \mathrm{~S}, \mathrm{Fe}^{*} \mathrm{Mn} * \mathrm{Mn}$ & n.s. \\
\hline $\mathrm{Ca}$ & $\mathrm{N}^{*} \mathrm{~N} * \mathrm{~S}, \mathrm{Fe}^{*} \mathrm{Mn}{ }^{*} \mathrm{Mn}$ & n.s. \\
\hline S (to leaves only) & $\mathrm{N} * \mathrm{~S} * \mathrm{~S}$ & n.s. \\
\hline$S$ & $\mathrm{~N} * \mathrm{~N} * \mathrm{~S}$ & n.s. \\
\hline $\mathrm{Zn}$ & n.s. & n.s. \\
\hline $\mathrm{Mn}$ & $\mathrm{Fe}^{*} \mathrm{Mn} * \mathrm{Mn}$ & $\mathrm{N} * \mathrm{Fe}^{*} \mathrm{Mn}$ \\
\hline $\mathrm{Cu}$ & n.s & n.s. \\
\hline $\mathrm{Fe}$ & $\mathrm{N}^{*} \mathrm{~S} * \mathrm{~S}$ & n.s. \\
\hline $\mathrm{B}$ & $\mathrm{Fe}^{*} \mathrm{Mn} * \mathrm{Mn}$ & $\mathrm{N} * \mathrm{~S} * \mathrm{Fe}$ \\
\hline $\mathrm{Cl}$ & $\mathrm{N}^{*} \mathrm{Mn}{ }^{*} \mathrm{Mn}, \mathrm{S} * \mathrm{~S} * \mathrm{Fe}, \mathrm{Fe}^{*} \mathrm{Fe}^{*} \mathrm{Mn}$ & $\mathrm{N} * \mathrm{~S} * \mathrm{Fe}$ \\
\hline Mo & $\mathrm{N} * \mathrm{~N} * \mathrm{~S}, \mathrm{~N} * \mathrm{~S} * \mathrm{~S}$ & n.s. \\
\hline
\end{tabular}

Table 2: Roots

\begin{tabular}{|c|c|c|}
\hline $\begin{array}{l}\text { Response } \\
\text { Variable }\end{array}$ & & \\
\hline $\begin{array}{c}\text { Elemental } \\
\text { Concentration } \\
\text { in leaves }\end{array}$ & Significant non-linear 2-way or & $\begin{array}{c}\geq 3 \text {-way } \\
\text { interactions }\end{array}$ \\
\hline 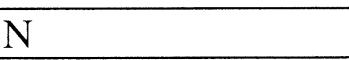 & $\mathrm{N}^{*} \mathrm{~N}^{*} \mathrm{~S}, \mathrm{~N}^{*} \mathrm{~N}^{*} \mathrm{Fe}, \mathrm{S} * \mathrm{Fe} * \mathrm{Fe}, \mathrm{S} * \mathrm{Mn} * \mathrm{Mn}$ & n.s. \\
\hline $\mathrm{P}$ & $\mathrm{N} * \mathrm{~N} * \mathrm{Fe}, \mathrm{N} * \mathrm{~S} * \mathrm{~S}, \mathrm{~S} * \mathrm{~S} * \mathrm{Fe}$ & n.s. \\
\hline $\mathrm{Al}$ & $\mathrm{S} * \mathrm{~S} * \mathrm{Fe}$ & n.s. \\
\hline $\mathrm{K}$ & $\mathrm{N} * \mathrm{~S} * \mathrm{~S}$ & n.s. \\
\hline $\mathrm{Mg}$ & $\mathrm{S} * \mathrm{~S} * \mathrm{M}$ & n.s. \\
\hline $\mathrm{Ca}$ & $\mathrm{N}^{*} \mathrm{~N}^{*} \mathrm{Fe}, \mathrm{N} * \mathrm{~S} * \mathrm{~S}, \mathrm{~S} * \mathrm{~S} * \mathrm{Fe}, \mathrm{S} * \mathrm{~S} * \mathrm{M}$ & n.s. \\
\hline $\mathrm{Na}$ & $\mathrm{N} * \mathrm{~S} * \mathrm{~S}, \mathrm{~N} * \mathrm{Mn} * \mathrm{Mn}, \mathrm{S} * \mathrm{~S} * \mathrm{Fe}$ & $\mathrm{N} * \mathrm{~S} * \mathrm{Mn}$ \\
\hline $\mathrm{S}$ & n.s. & n.s. \\
\hline $\mathrm{Zn}$ & $\mathrm{N} * \mathrm{~S} * \mathrm{~S}$ & n.s. \\
\hline $\mathrm{Mn}$ & n.s. & n.s. \\
\hline $\mathrm{Cu}$ & n.s. & n.s. \\
\hline $\mathrm{Fe}$ & $\mathrm{S} * \mathrm{~S} * \mathrm{Fe}$ & n.s. \\
\hline $\mathrm{B}$ & $\mathrm{N} * \mathrm{~S} * \mathrm{~S}$ & $\mathrm{~S} * \mathrm{Fe} * \mathrm{Mn}$ \\
\hline $\mathrm{Cl}$ & n.s. & n.s. \\
\hline Mo (only 6 pts) & N/A & N/A \\
\hline
\end{tabular}


Table 3: Anova and Parameter Estimates For the Hoerl Model

Dependent Variable: B

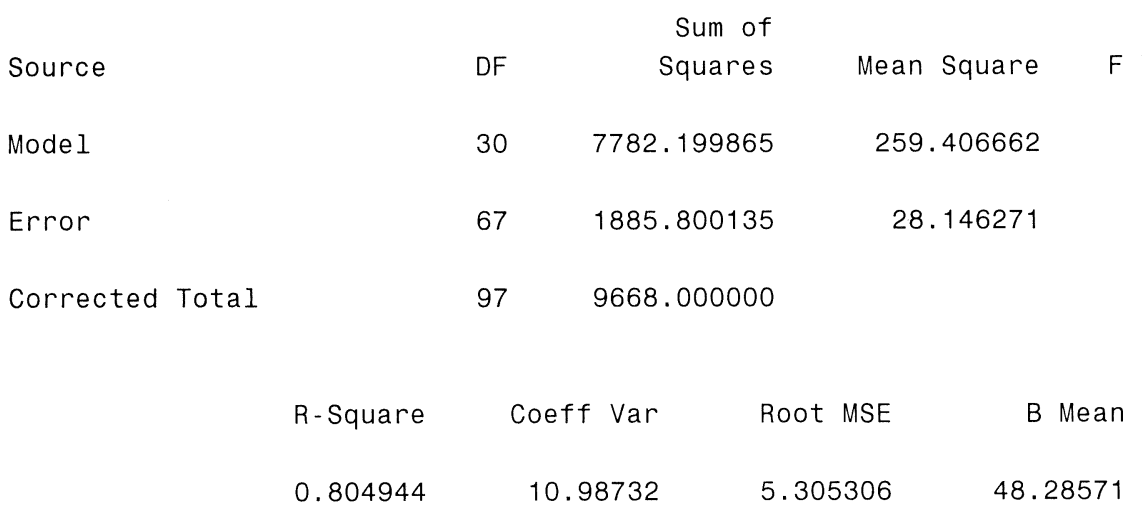

\begin{tabular}{|c|c|c|c|c|c|}
\hline Source & DF & Type I SS & Mean Square & F Value & $\mathrm{Pr}>\mathrm{F}$ \\
\hline$n$ & 1 & 3202.368858 & 3202.368858 & 113.78 & $<.0001$ \\
\hline s & 1 & 528.915375 & 528.915375 & 18.79 & $<.0001$ \\
\hline$i$ & 1 & 242.224074 & 242.224074 & 8.61 & 0.0046 \\
\hline $\mathrm{m}$ & 1 & 6.611173 & 6.611173 & 0.23 & 0.6295 \\
\hline $\operatorname{lnni}$ & 1 & 1019.145554 & 1019.145554 & 36.21 & $<.0001$ \\
\hline Ins & 1 & 656.780141 & 656.780141 & 23.33 & $<.0001$ \\
\hline $\operatorname{lnfe}$ & 1 & 5.710044 & 5.710044 & 0.20 & 0.6539 \\
\hline $\operatorname{lnmn}$ & 1 & 231.706233 & 231.706233 & 8.23 & 0.0055 \\
\hline ns & 1 & 572.354091 & 572.354091 & 20.33 & $<.0001$ \\
\hline in & 1 & 221.316456 & 221.316456 & 7.86 & 0.0066 \\
\hline $\mathrm{nm}$ & 1 & 38.682321 & 38.682321 & 1.37 & 0.2452 \\
\hline is & 1 & 60.246544 & 60.246544 & 2.14 & 0.1481 \\
\hline $\mathrm{sm}$ & 1 & 47.136176 & 47.136176 & 1.67 & 0.2001 \\
\hline im & 1 & 45.889515 & 45.889515 & 1.63 & 0.2061 \\
\hline $\operatorname{lnni*} \operatorname{lns}$ & 1 & 85.806941 & 85.806941 & 3.05 & 0.0854 \\
\hline $\operatorname{lnni} \operatorname{lnfe}$ & 1 & 12.154817 & 12.154817 & 0.43 & 0.5133 \\
\hline $\operatorname{lnni*} \operatorname{lnmn}$ & 1 & 66.737236 & 66.737236 & 2.37 & 0.1283 \\
\hline $\operatorname{lns}{ }^{*} \operatorname{lnfe}$ & 1 & 53.081896 & 53.081896 & 1.89 & 0.1742 \\
\hline $\operatorname{lns}{ }^{*} \operatorname{lnmn}$ & 1 & 7.859807 & 7.859807 & 0.28 & 0.5989 \\
\hline Infe lnmn & 1 & 127.001241 & 127.001241 & 4.51 & 0.0373 \\
\hline nsi & 1 & 253.958198 & 253.958198 & 9.02 & 0.0037 \\
\hline $\mathrm{nsm}$ & 1 & 67.492348 & 67.492348 & 2.40 & 0.1262 \\
\hline nim & 1 & 45.473645 & 45.473645 & 1.62 & 0.2081 \\
\hline sim & 1 & 0.386774 & 0.386774 & 0.01 & 0.9070 \\
\hline $\operatorname{lnni}{ }^{*} \operatorname{lns} s^{*} \operatorname{lnfe}$ & 1 & 0.077591 & 0.077591 & 0.00 & 0.9583 \\
\hline $\operatorname{lnni}{ }^{*} \operatorname{lns}{ }^{*} \operatorname{lnmn}$ & 1 & 20.877839 & 20.877839 & 0.74 & 0.3922 \\
\hline $\operatorname{lnni}{ }^{*} \operatorname{lnfe} e^{*} \operatorname{lnmn}$ & 1 & 99.071149 & 99.071149 & 3.52 & 0.0650 \\
\hline $\operatorname{lns}{ }^{*} \operatorname{lnfe} e^{*} \operatorname{lnmn}$ & 1 & 0.031655 & 0.031655 & 0.00 & 0.9733 \\
\hline nsim & 1 & 62.574135 & 62.574135 & 2.22 & 0.1406 \\
\hline $\operatorname{lnni}{ }^{*} \operatorname{lns}{ }^{*} \operatorname{lnfe} e^{*} \operatorname{lnmn}$ & 1 & 0.528037 & 0.528037 & 0.02 & 0.8915 \\
\hline
\end{tabular}




\section{Applied Statistics in Agriculture}

Table 3: Anova and Parameter Estimates For the Hoerl Model

\begin{tabular}{|c|c|c|c|c|}
\hline & & standard & & \\
\hline Parameter & Estimate & Error & $t$ Value & $\operatorname{Pr}>|t|$ \\
\hline Intercept & 45.8813192 & 49.1916856 & 0.93 & 0.3543 \\
\hline $\mathrm{n}$ & -0.0281737 & 0.1165883 & -0.24 & 0.8098 \\
\hline s & 0.9727138 & 0.7879712 & 1.23 & 0.2213 \\
\hline$i$ & -13.9916757 & 7.5894017 & -1.84 & 0.0697 \\
\hline $\mathrm{m}$ & -58.2398713 & 17.4653971 & -3.33 & 0.0014 \\
\hline $\operatorname{lnni}$ & 2.8328072 & 13.5378441 & 0.21 & 0.8349 \\
\hline $\operatorname{lns}$ & 15.0557245 & 21.2920881 & 0.71 & 0.4820 \\
\hline Infe & 90.4184192 & 59.7392387 & 1.51 & 0.1348 \\
\hline $\operatorname{lnmn}$ & 275.6323193 & 101.2676949 & 2.72 & 0.0083 \\
\hline ns & -0.0002053 & 0.0054016 & -0.04 & 0.9698 \\
\hline in & 0.0734745 & 0.0539613 & 1.36 & 0.1779 \\
\hline $\mathrm{nm}$ & 0.2612944 & 0.1163349 & 2.25 & 0.0280 \\
\hline is & -0.1813872 & 0.3885696 & -0.47 & 0.6422 \\
\hline $\mathrm{sm}$ & 0.2232097 & 0.8010788 & 0.28 & 0.7814 \\
\hline im & 16.5241811 & 7.7192362 & 2.14 & 0.0359 \\
\hline $\operatorname{lnni} i^{*} \operatorname{lns}$ & -5.2609838 & 4.5224583 & -1.16 & 0.2488 \\
\hline $\operatorname{lnni}{ }^{*} \operatorname{lnfe}$ & -18.0298225 & 12.9104337 & -1.40 & 0.1672 \\
\hline $\operatorname{lnni} i^{*} \operatorname{lnmn}$ & -49.1538873 & 21.5408161 & -2.28 & 0.0257 \\
\hline $\operatorname{lns} * \operatorname{lnfe}$ & 2.8357163 & 21.5869768 & 0.13 & 0.8959 \\
\hline $\operatorname{lns} \mathrm{ln}^{\star} \operatorname{lnm}$ & -20.4448459 & 34.3513593 & -0.60 & 0.5537 \\
\hline $\operatorname{lnfe} e^{\star} \operatorname{lnmn}$ & -171.2306149 & 97.6344470 & -1.75 & 0.0840 \\
\hline nsi & 0.0006724 & 0.0026637 & 0.25 & 0.8015 \\
\hline $\mathrm{nsm}$ & -0.0036791 & 0.0054607 & -0.67 & 0.5028 \\
\hline nim & -0.0865567 & 0.0537258 & -1.61 & 0.1119 \\
\hline sim & -0.2796512 & 0.3964660 & -0.71 & 0.4830 \\
\hline $\operatorname{lnni}{ }^{*} \operatorname{lns}{ }^{*} \operatorname{lnfe}$ & -0.0150084 & 4.5950414 & -0.00 & 0.9974 \\
\hline $\operatorname{lnni}{ }^{*} \operatorname{lns}{ }^{*} \operatorname{lnmn}$ & 4.7262346 & 7.2819407 & 0.65 & 0.5185 \\
\hline $\operatorname{lnni}{ }^{*} \operatorname{lnfe} e^{*} \operatorname{lnmn}$ & 31.5130653 & 20.8717732 & 1.51 & 0.1358 \\
\hline $\operatorname{lns}{ }^{*} \operatorname{lnfe} e^{*} \operatorname{lnmn}$ & 5.5261972 & 34.8715171 & 0.16 & 0.8746 \\
\hline nsim & 0.0019622 & 0.0026769 & 0.73 & 0.4661 \\
\hline $\operatorname{lnni}{ }^{*} \operatorname{lns} \ln ^{\prime} \ln e^{*} \operatorname{lnmn}$ & -1.0123911 & 7.3913989 & -0.14 & 0.8915 \\
\hline
\end{tabular}


Figure $1 . \mathrm{N} \times \mathrm{S}$ means of leaf area for Macz data.

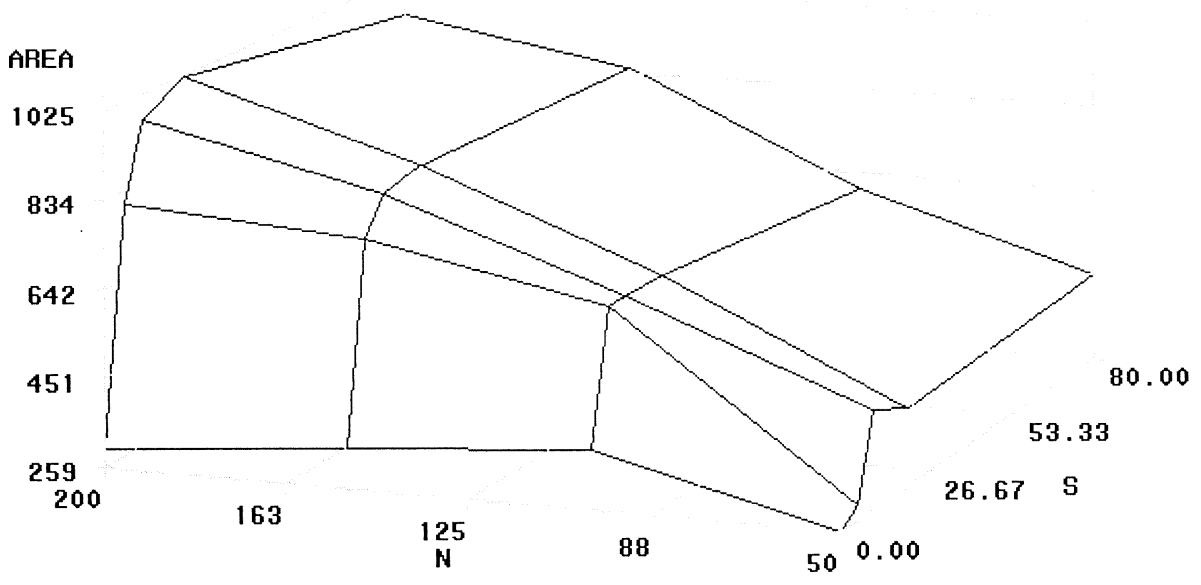


Figure 2. Macz leaf area data: predicted values from two models.

Model 1: second-order polynomial regression

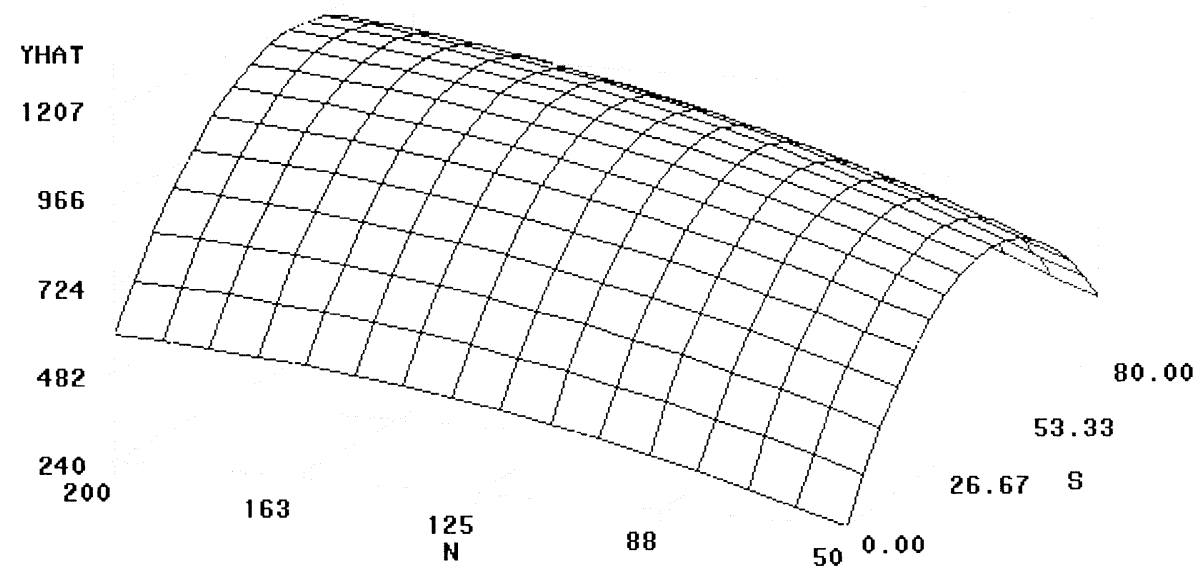

Model 2: Model with Gompertz response for S, linear response for $\mathrm{N}$

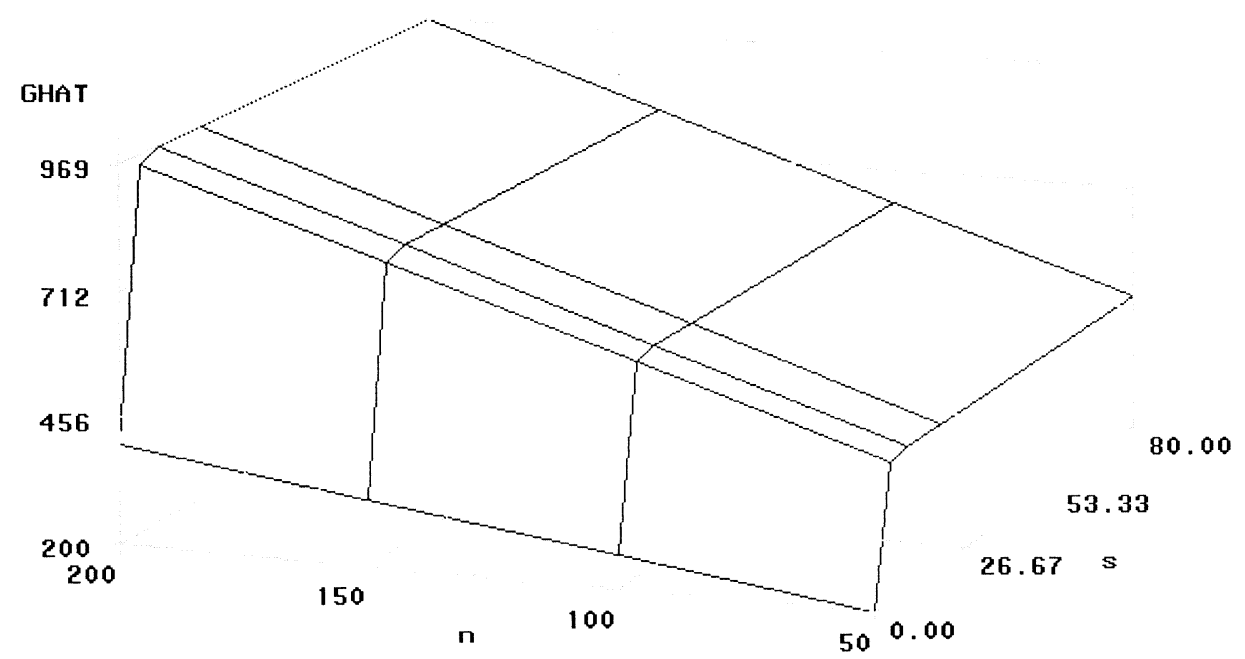


Figure 3. Illustration of three-way interaction*

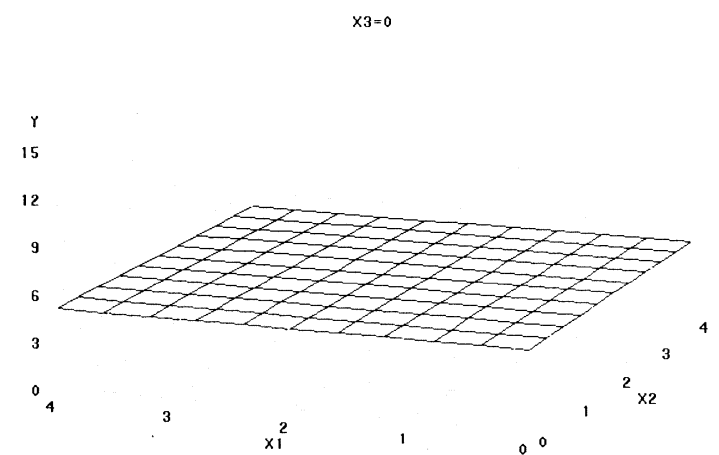

at $X_{3}=0$

$x 3=2$

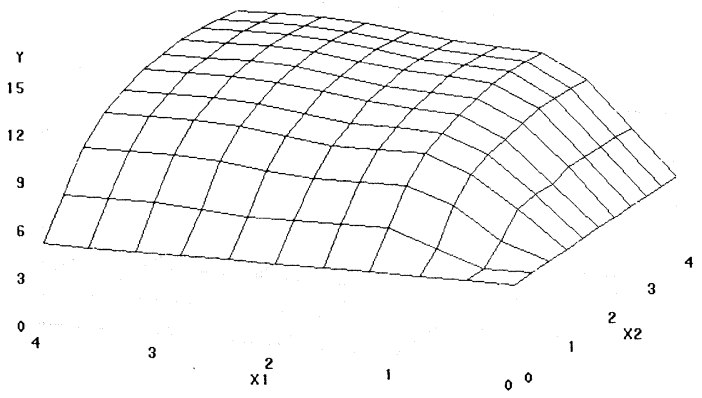

at $X_{3}=2$ $x 3=1$

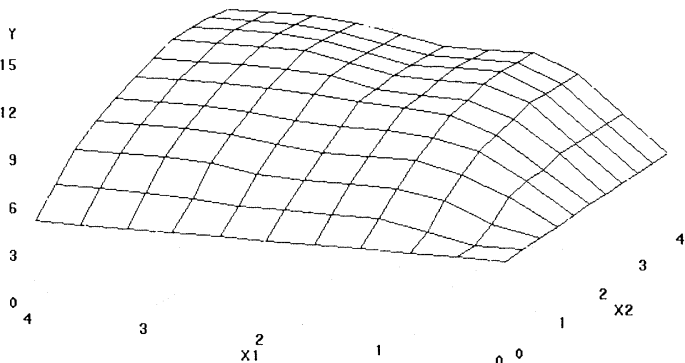

at $\mathrm{X}_{3}=1$

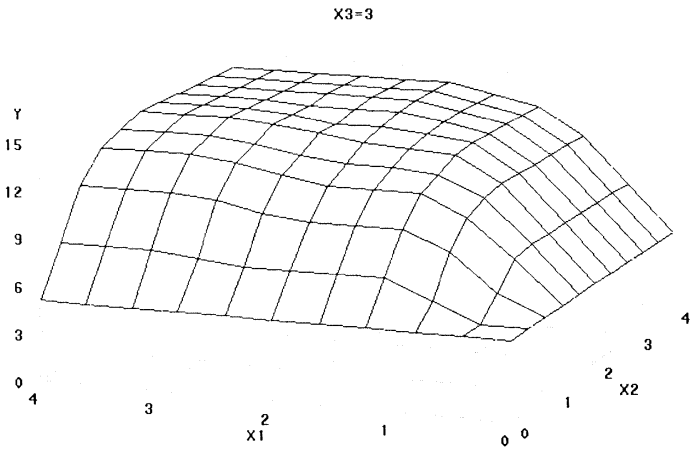

at $X_{3}=3$

$x 3=4$

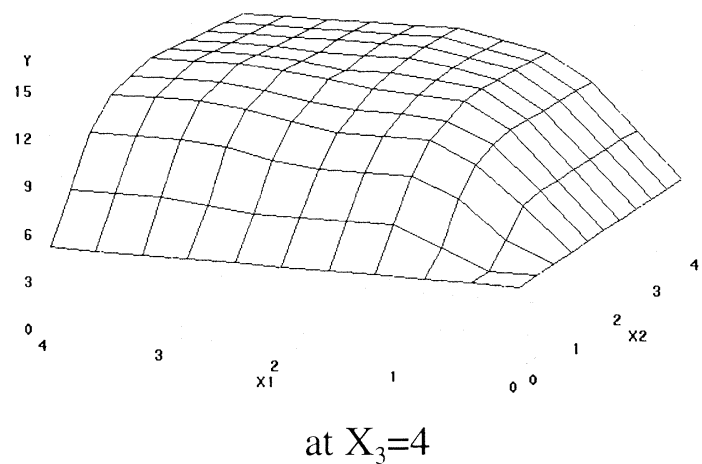

* $\quad \mathrm{X}_{1}, \mathrm{X}_{2}, \mathrm{X}_{3}$ denote three nutrients. Each applied at 5 levels: 0, 1, 2, 3, and 4 units. Lowest level (0) is limiting for response. 
Figure 4. Three factor Mitscherlich and Gompertz models - Fit of $X_{1} \times X_{2}$ Surface by level of $X_{3}$

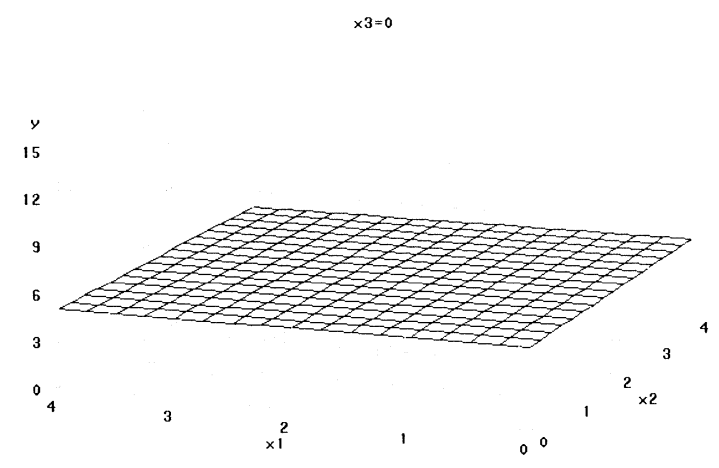

$$
\text { at } X_{3}=0
$$

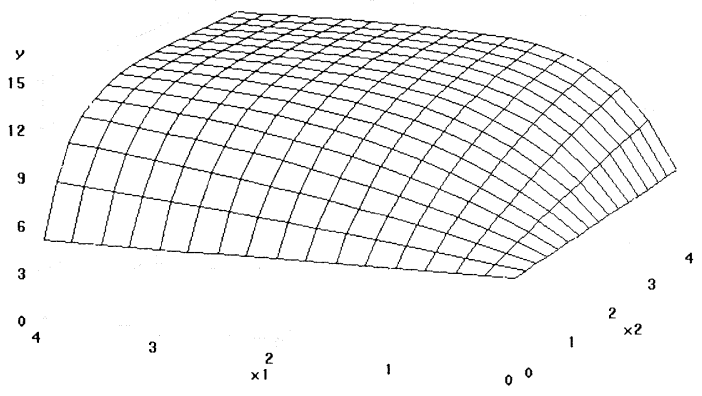

at $\mathrm{X}_{3}=2$

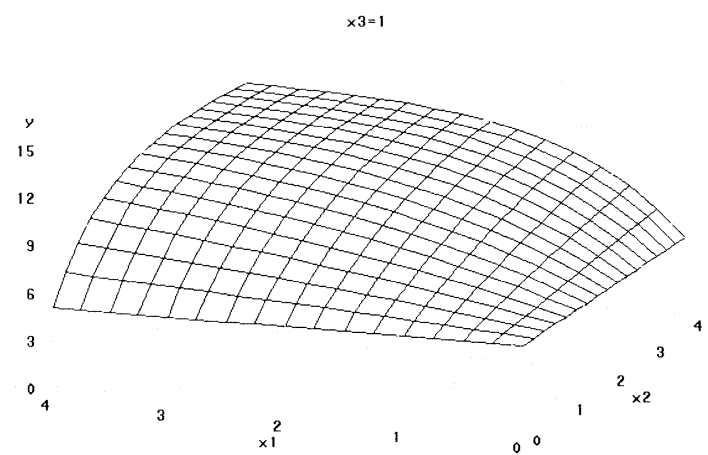

at $X_{3}=1$

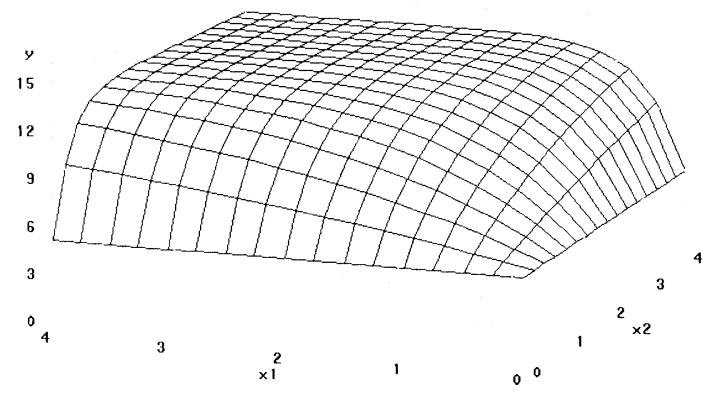

$\times 3=4$

at $\mathrm{X}_{3}=3$

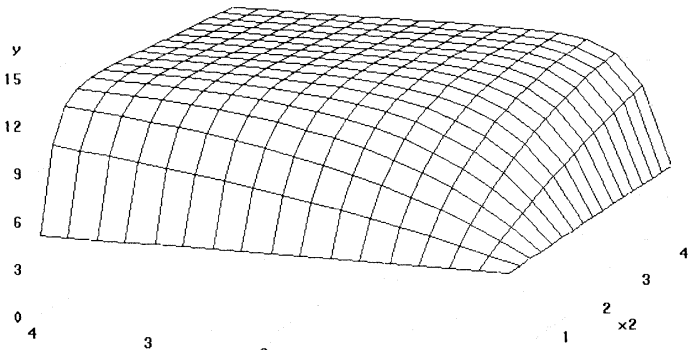

at $X_{3}=4$ 
Figure 5. Fit of Hoerl Regression equation to 3-factor data

LEAF AREA AT 8 WKS SDI (FALL 96)

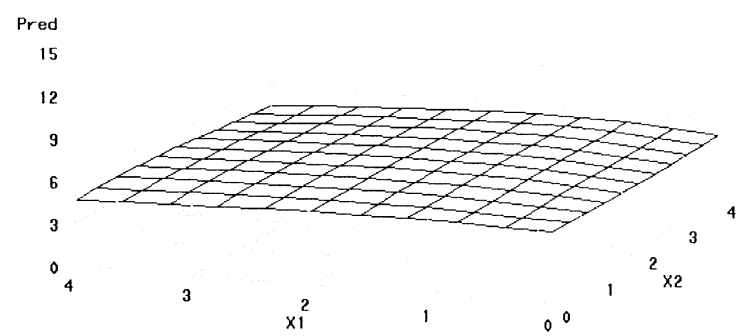

at $\mathrm{X}_{3}=0$

LEAF AREA AT 8 WKS SDI (FALL 96) $\times 3=2$

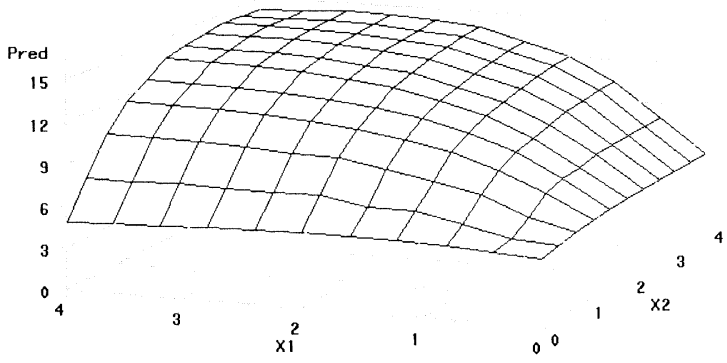
LEAF AREA AT 8 WKS SDI (FALL 96)

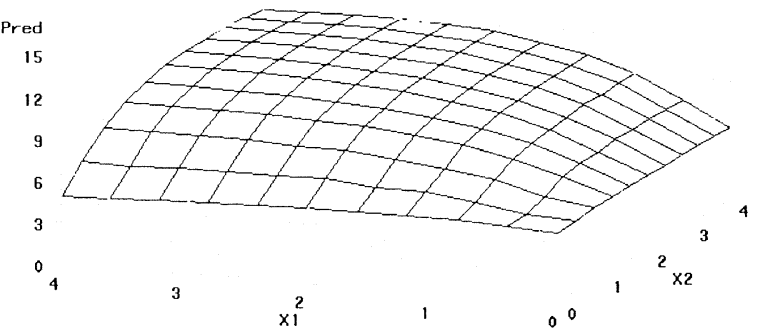

at $X_{3}=1$

LEAF AREA AT 8 WKS SDI (FALL 96)

$X_{3}=3$

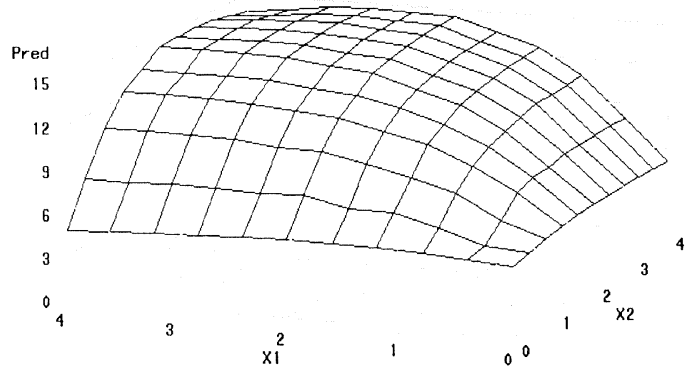

at $\mathrm{X}_{3}=2$

at $\mathrm{X}_{3}=3$

LEAF AREA AT 8 WKS SDI (FALL 96)

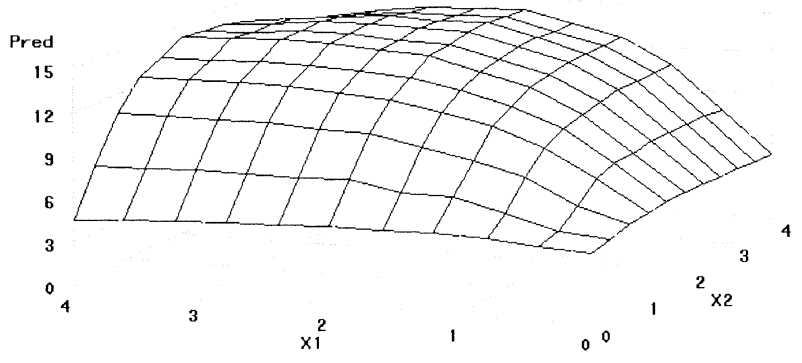

at $X_{3}=4$ 
Figure 6: Scatter Plot of Boron data

$$
\text { Baron - Shods }
$$

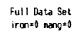

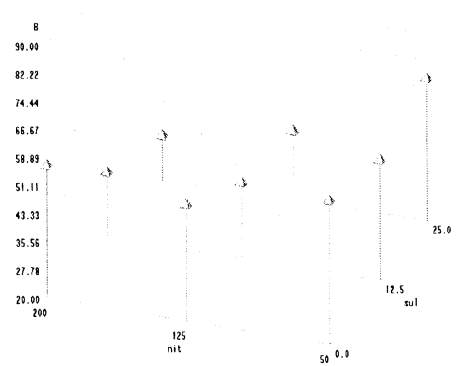

Baron - Shods

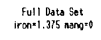

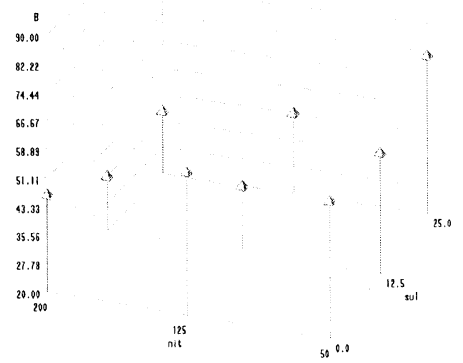

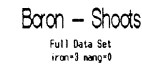

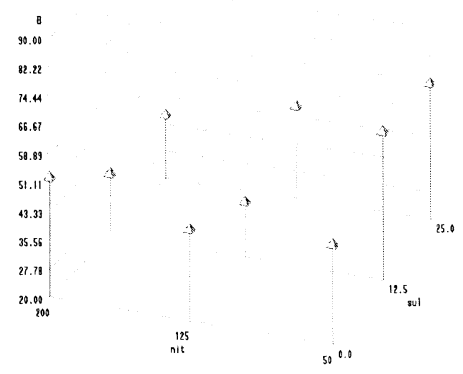

Boron - Shoots

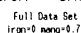

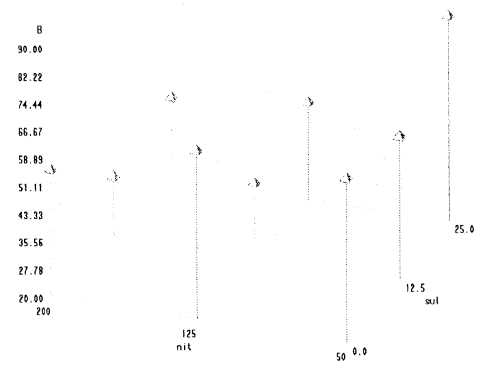

Boron - Shoots

Fut1 latt set.

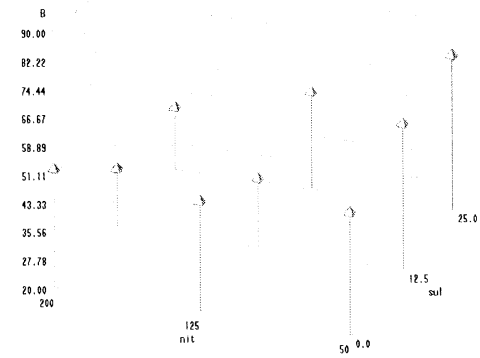

Baron - Shoots



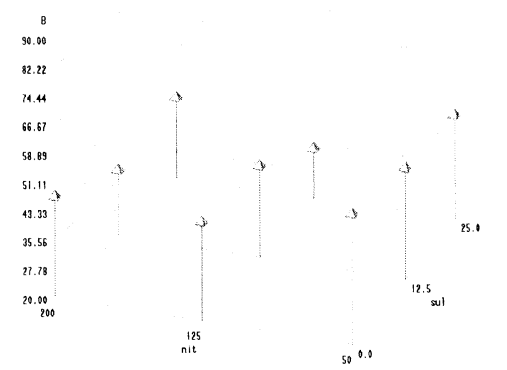

Baron - Shoots

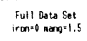


Figure 7: Another View of Original Data
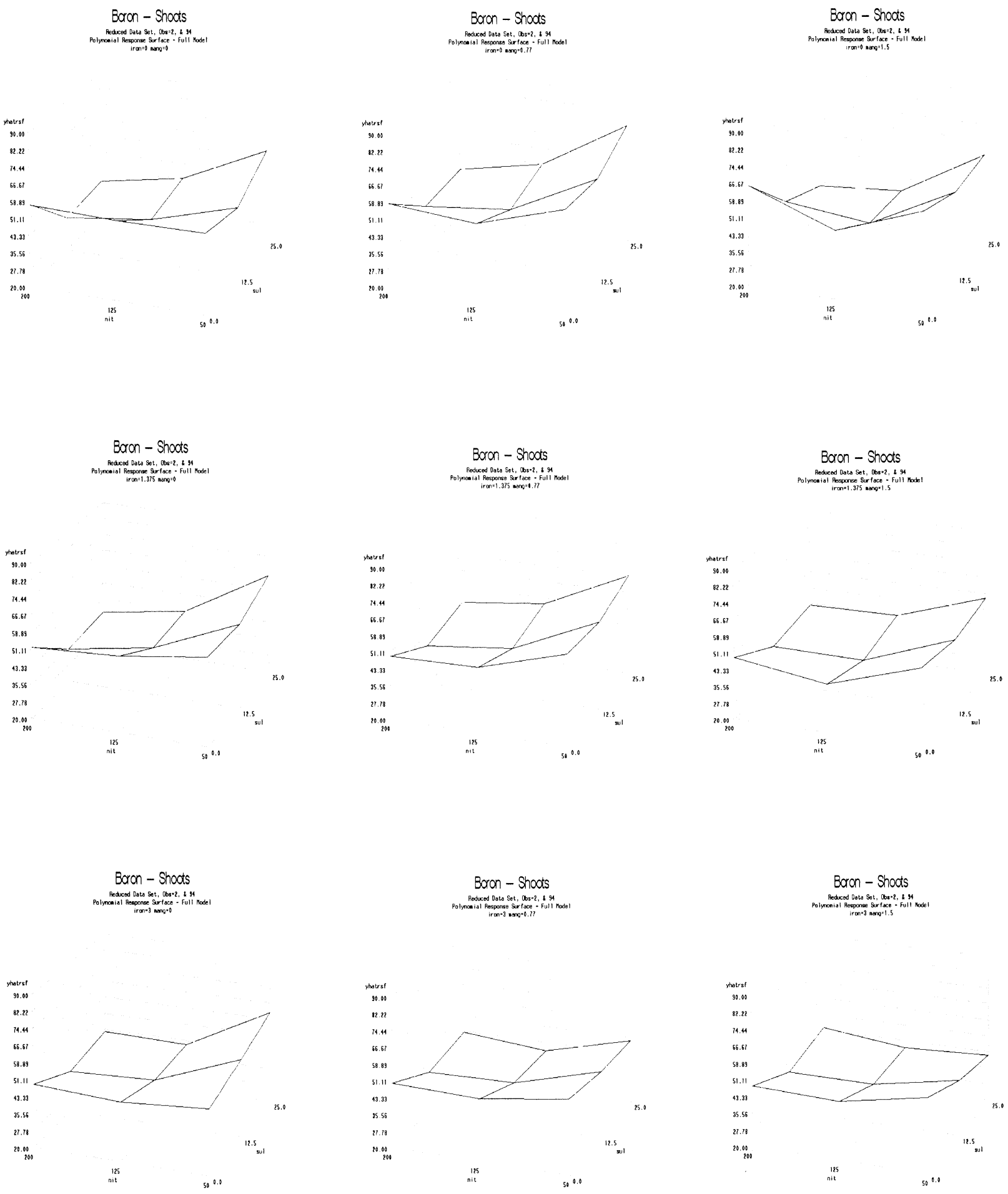
Figure 8: Second Order Response Surface - Second Order Terms Only
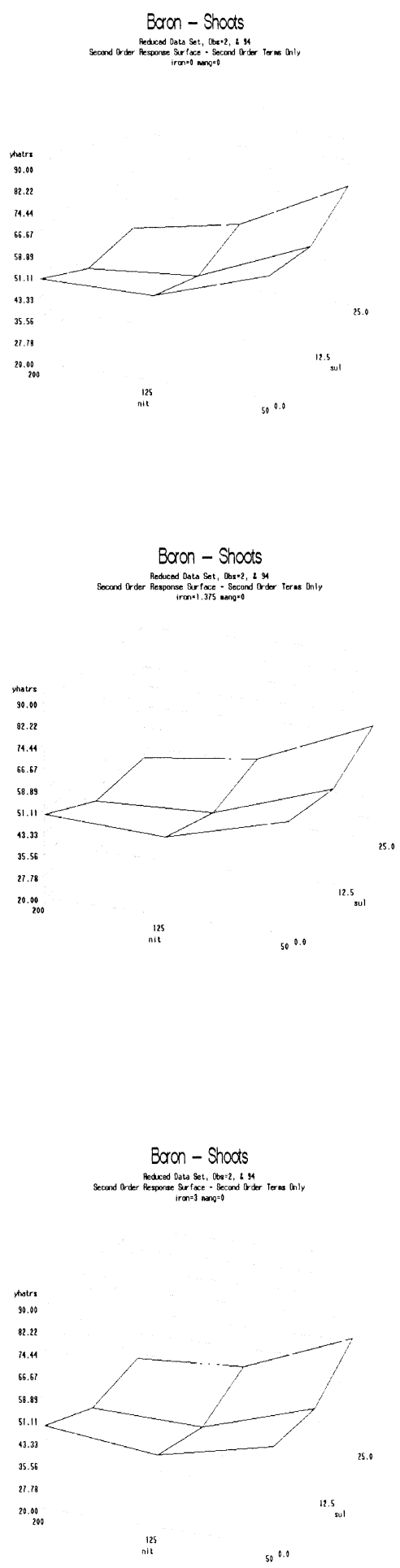
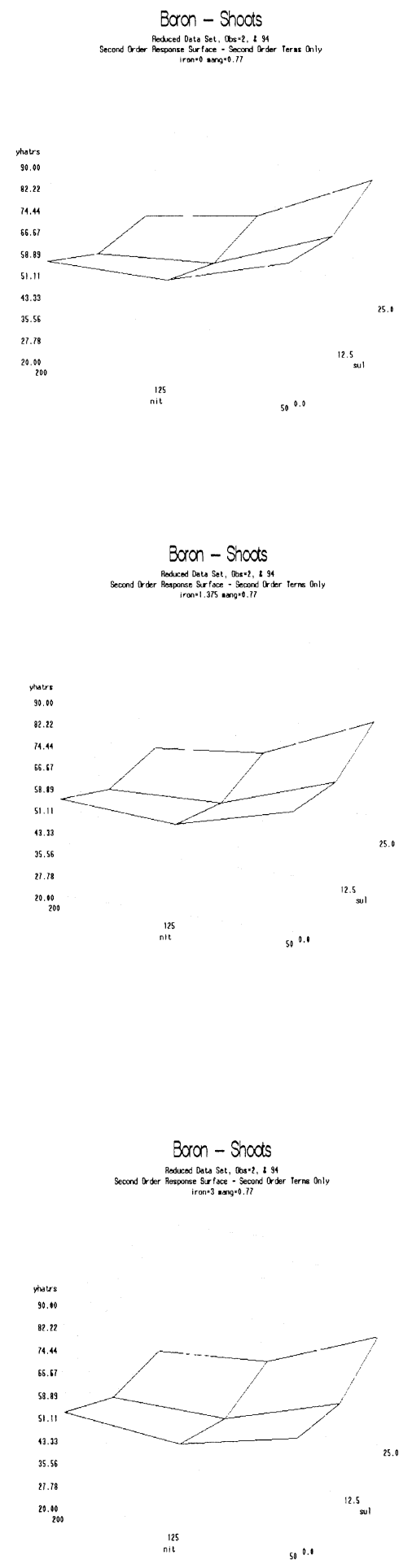
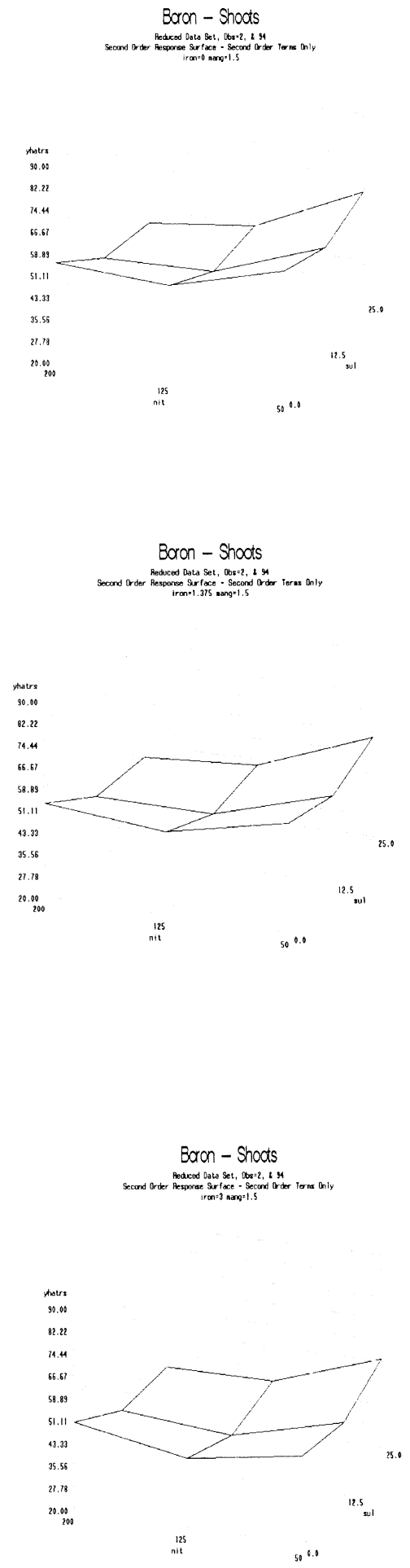
Figure 9: Augmented Response Surface - Significant Terms Only
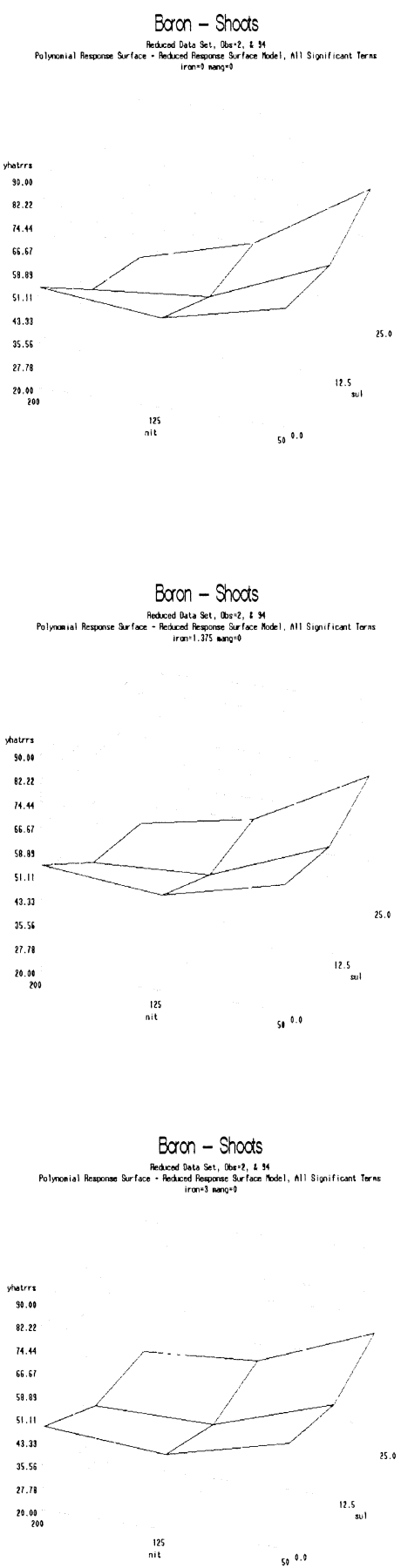
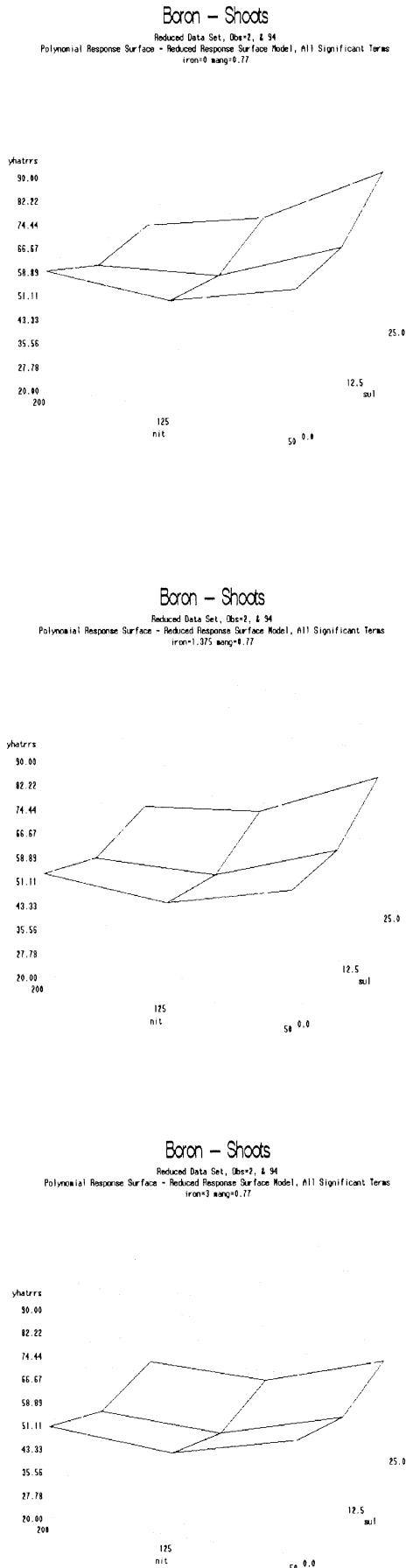
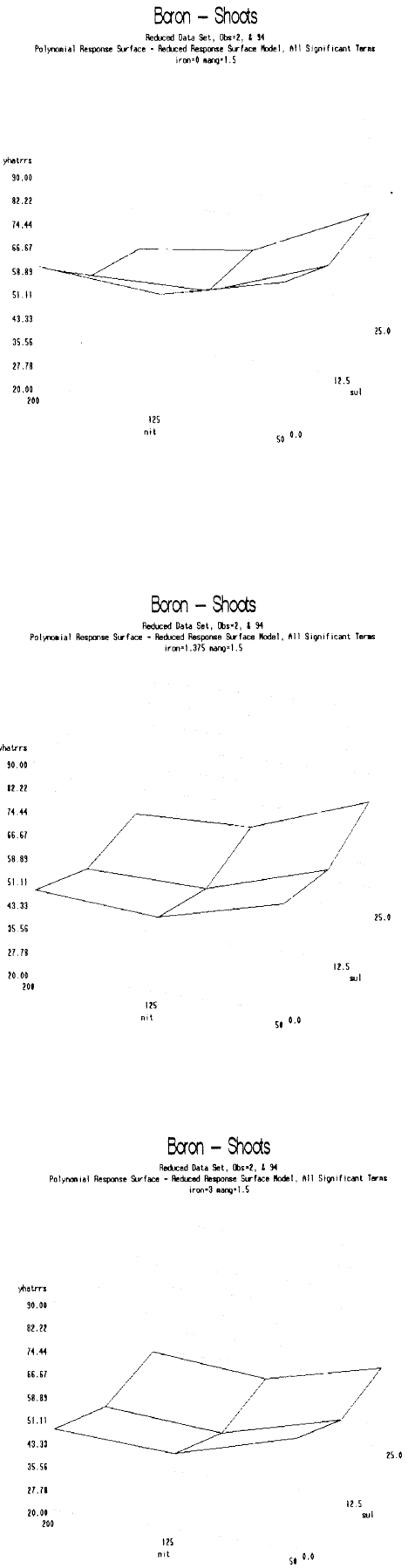
Figure 10: Hoerl Full Model

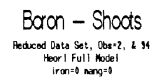

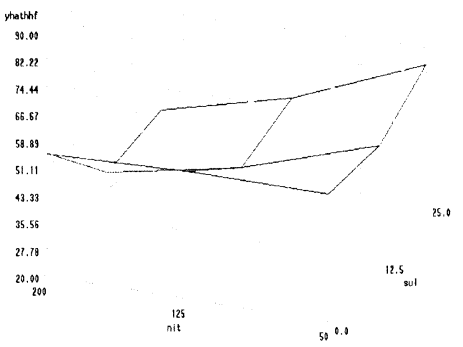

Baron - Shoods

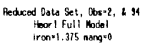

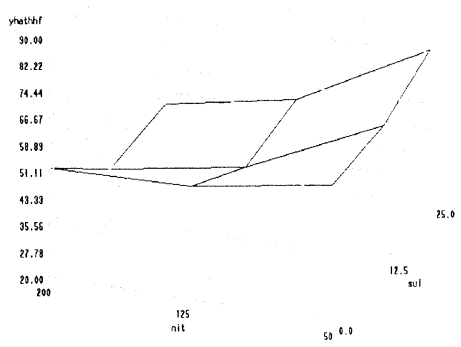

Beron - Shoots

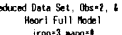

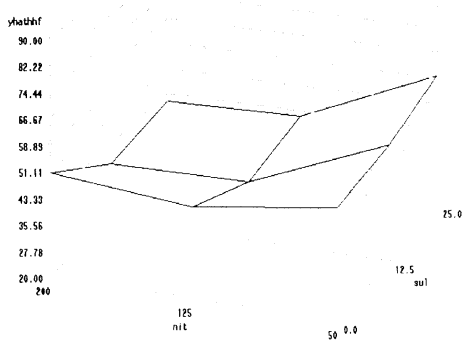

Baron - Shoots

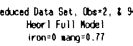

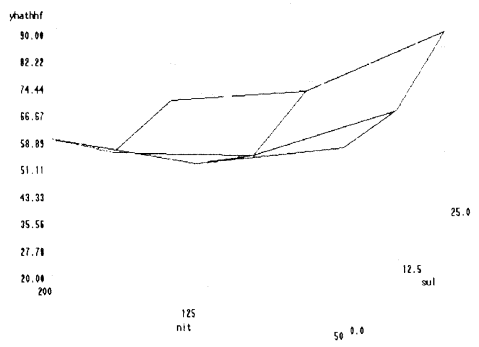

Baron - Shods

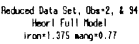

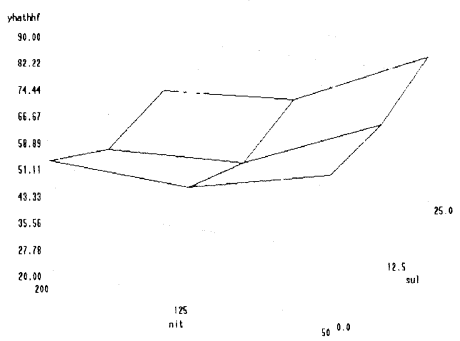

Boron - Shoots

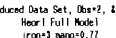

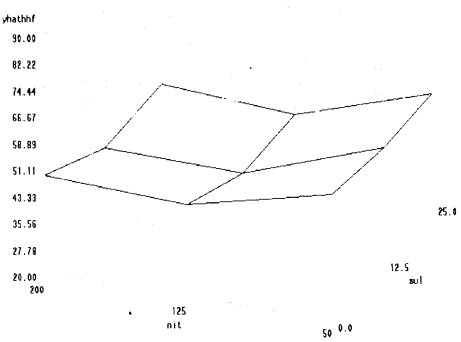

Baron - Shoods

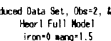

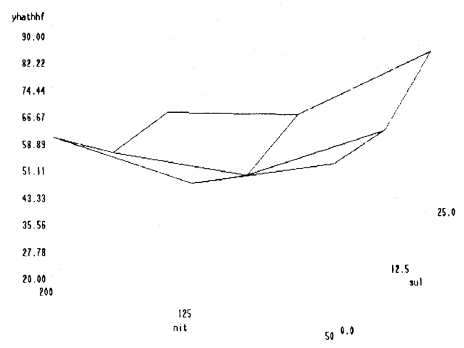

Baron - Shoots

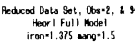

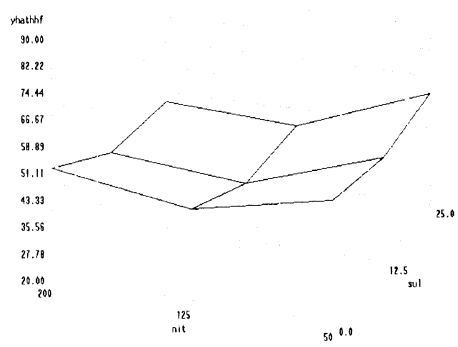

Baron - Shods

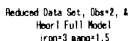

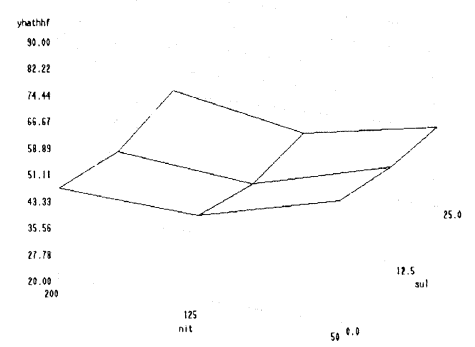


Figure 11: 3D Representation of CELEPSO

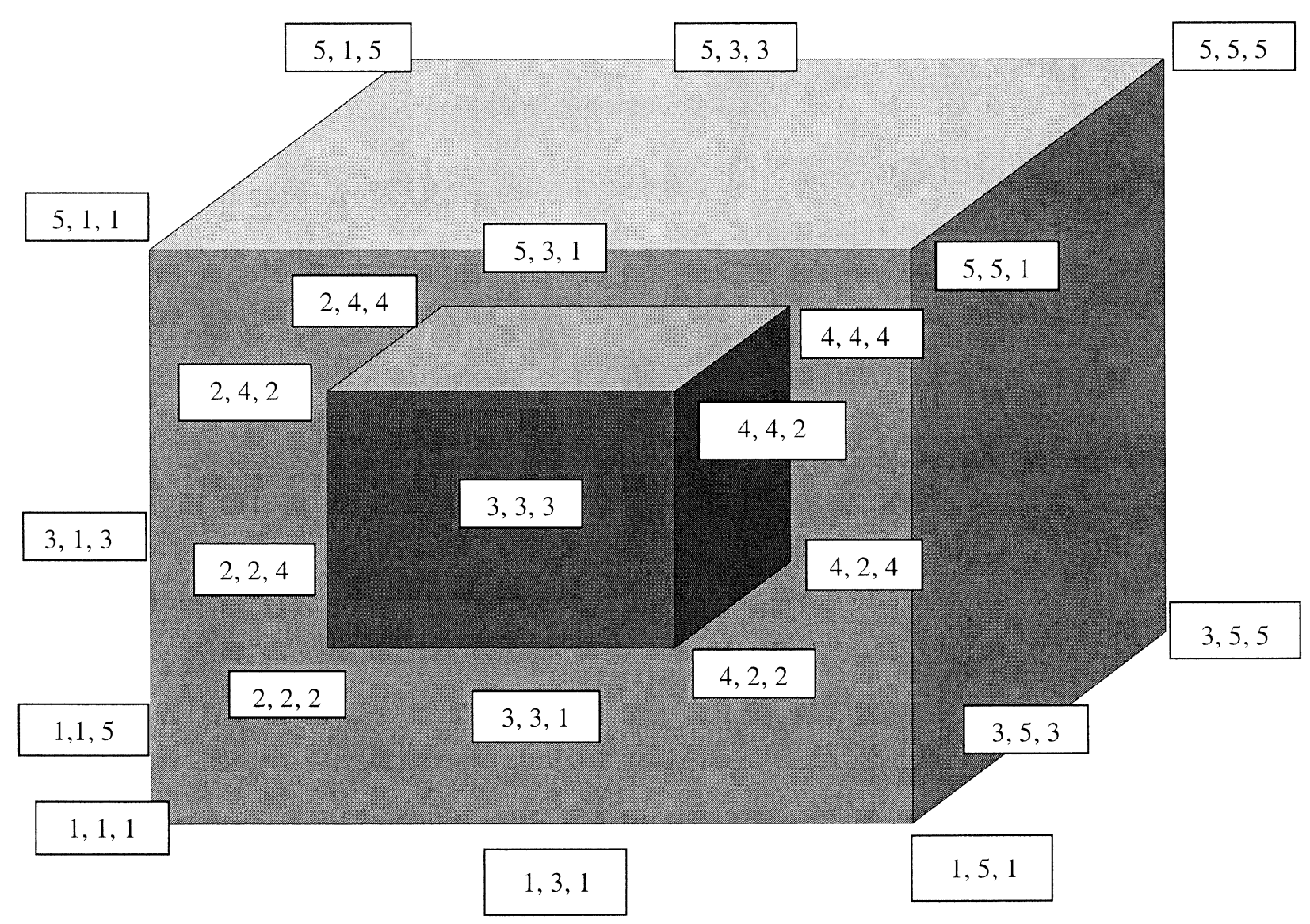


Figure 12: Second Order Response Surface - Second Order Terms Only (CELEPSO Data Set)
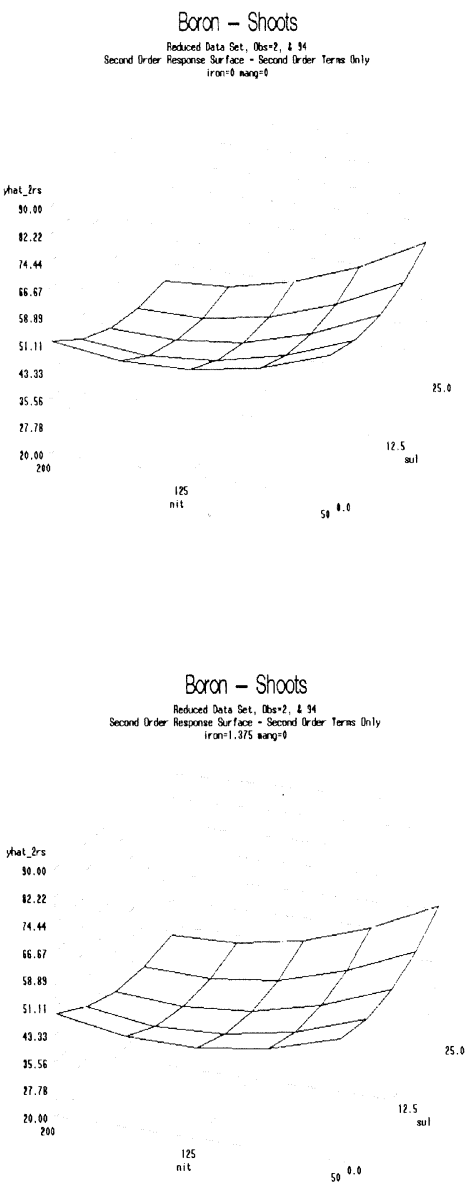

Boron - Shoots

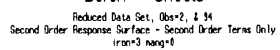

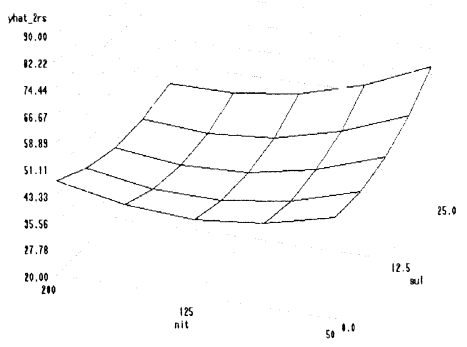

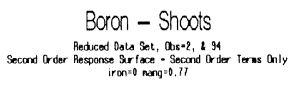

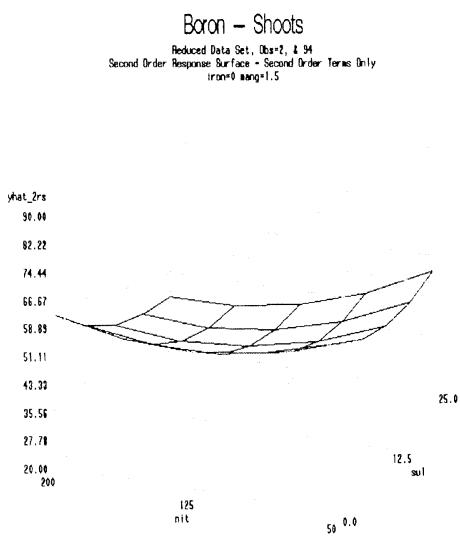

Boron - Shoots
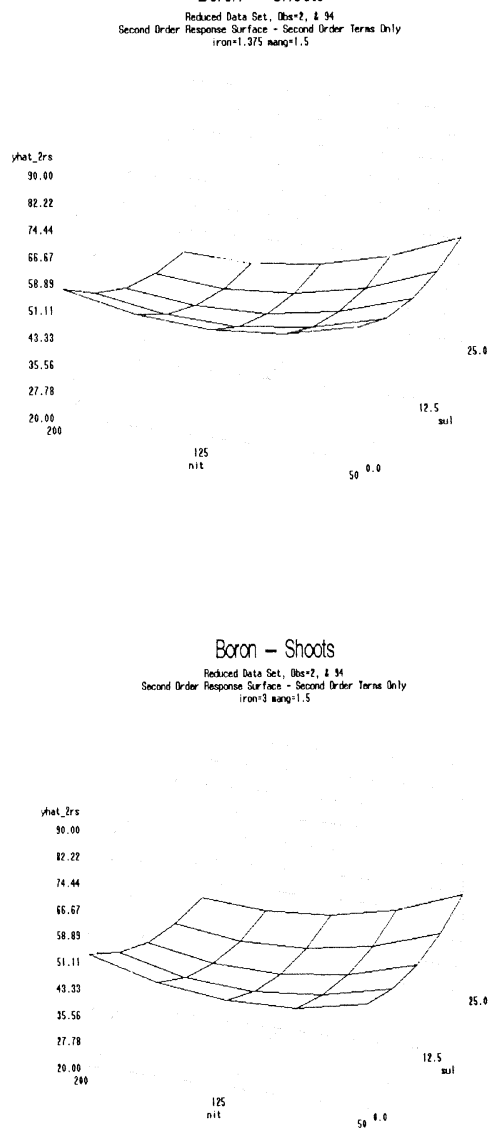
Figure 13: Horel Model (CELEPSO Data Set)

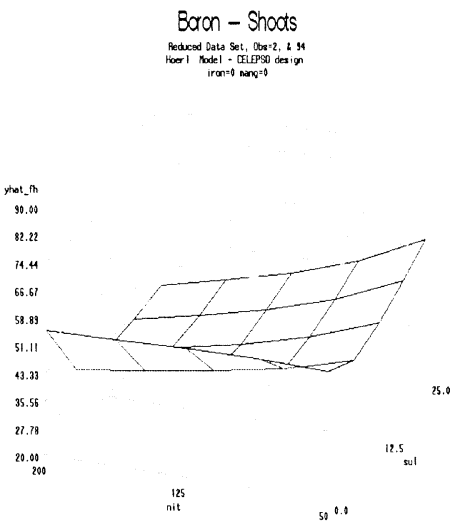

Baron - Shoots

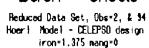

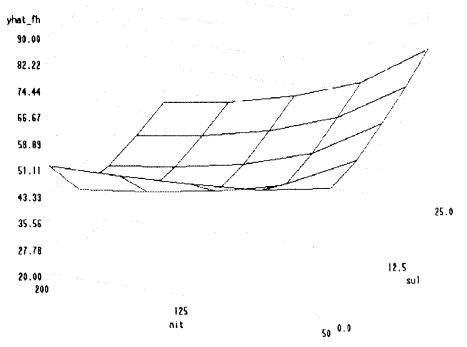

Baron - Shoods

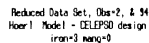

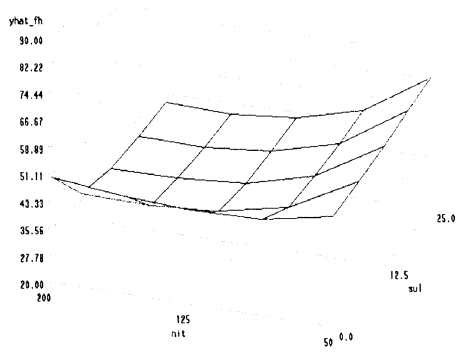

Boron - Shoots

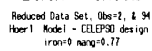

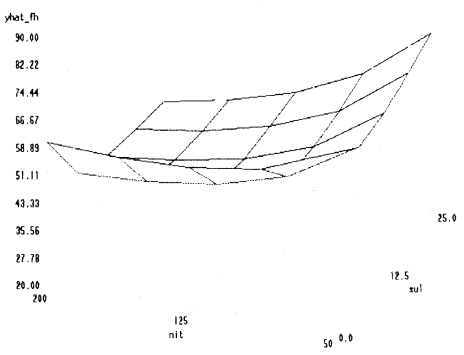

Baron - Shoots

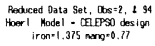

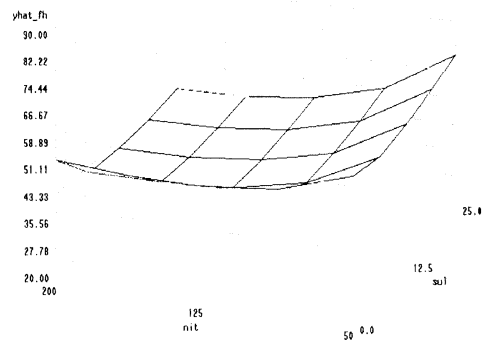

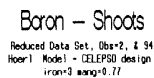

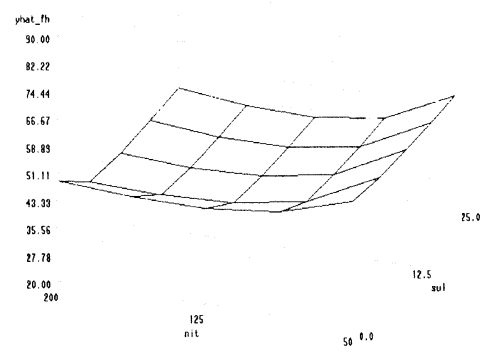

Baron - Shoots

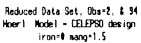

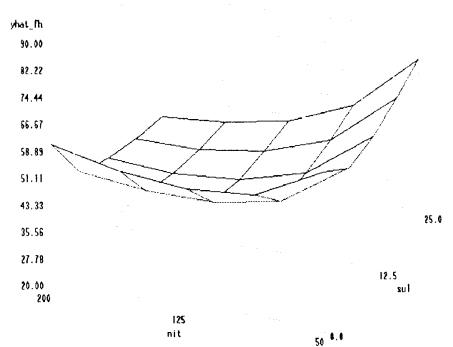

Baron - Shoots

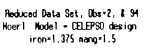

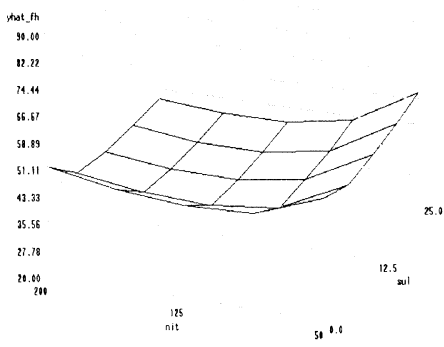

Baron - Shods

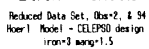

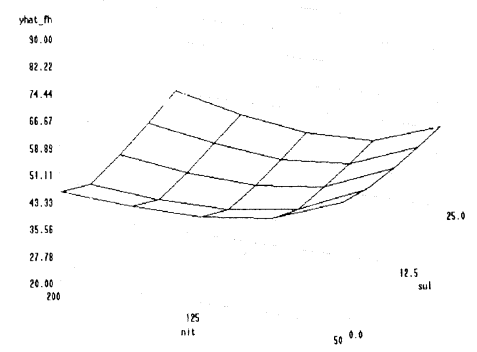

